\title{
Valve-sparing aortic root replacement in children
}

\author{
Sandeep S. Rakhra, BMedSci, Christian P. Brizard, MD, Yves d'Udekem, MD, PhD, and \\ Igor E. Konstantinov, MD, PhD, Melbourne, Australia
}

Aortic root dilatation is uncommon in children, with most cases related to congenital heart disease and its repair or to connective tissue disorders. ${ }^{1-3}$ It rarely causes severe aortic insufficiency or dissection. ${ }^{4}$ There are no clear indications for aortic root replacement in asymptomatic children. However, many clinicians would suggest replacing a significantly dilated root when an adult size graft can be implanted. The valve-sparing aortic root replacement has obvious advantages over composite graft and homograft root replacement and is progressively being introduced for pediatric root replacement. The long-term durability of this technique in children has not been defined, and the current literature has suggested that the valve-sparing procedures, especially root remodeling, may have a high failure rate..$^{1-3}$

\section{CLINICAL SUMMARY}

This study was approved by The Royal Children's Hospital Human Research Ethics Committee. From February 2002 to October 2011, 10 patients underwent valve-sparing aortic root replacement. The median age and weight at operation was 15 years (range, 7-18 years) and $57 \mathrm{~kg}$ (range, 17-70 $\mathrm{kg}$ ), respectively. Patient characteristics are shown in Table 1.

The $z$ scores were determined as previously described. ${ }^{5}$ Preoperative mean aortic annulus, sinus, and sinotubular junction measurements were $28 \pm 9 \mathrm{~mm}$ ( $z$ score, $3.3 \pm 2.8), 48 \pm 10 \mathrm{~mm}$ ( $z$ score, $5.9 \pm 1.6)$, and $38 \pm 11$ $\mathrm{mm}$ ( $z$ score, $5.5 \pm 2.5$ ), respectively. Preoperative aortic regurgitation was trivial $(\mathrm{n}=2)$, mild $(\mathrm{n}=6)$, moderate $(\mathrm{n}=1)$, and severe $(\mathrm{n}=1)$.

Nine patients had an elective procedure. One patient had an acute aortic dissection while being monitored for progressive aortic root dilatation and required a lifesaving operation. This patient has been reported by Konstantinov and colleagues. ${ }^{4}$

Remodeling was only performed in the first patient with a Haemashield Intervascular conduit (Maquet, Rastatt,

From the Cardiac Surgery Unit, Department of Paediatrics, University of Melbourne and Murdoch Children's Research Institute, Royal Children's Hospital, Melbourne, Australia.

Yves d'Udekem is a Career Development Fellow of The National Heart Foundation of Australia (CR 10M 5339). This research project was supported by the Victorian Government's Operational Infrastructure Support Program.

Disclosures: Authors have nothing to disclose with regard to commercial support.

Received for publication March 18, 2012; revisions received April 27, 2012; accepted for publication May 16, 2012; available ahead of print June 19, 2012.

Address for reprints: Igor E. Konstantinov, MD, PhD, Royal Children's Hospital, Flemington Rd, Parkville, Victoria 3052, Australia (E-mail: igor.konstantinov@rch. org.au).

J Thorac Cardiovasc Surg 2012;144:980-1

$0022-5223 / \$ 36.00$

Crown Copyright (C) 2012 Published by Elsevier Inc. on behalf of The American Association for Thoracic Surgery

http://dx.doi.org/10.1016/j.jtcvs.2012.05.038

Germany). The other patients had reimplantation using the Valsalva graft (Terumo Cardiovascular Systems Corp, Ann Arbor, Mich). The patient with Takayasu arteritis required a Vascutek Plexus graft (Terumo Cardiovascular Systems Corp) for an ascending aorta and arch replacement.

There were no operative deaths. All patients received aspirin for 3 months. Concurrent follow-up was obtained in all patients for a median length of 4.1 years (mean, 3.9; range, 0.1-8.8 years). There were no late deaths.

There were 3 reoperations (Table 1). Patient 1 with Marfan syndrome required a Bentall procedure for severe aortic regurgitation 4 years after root remodeling. Patient 2 underwent root replacement 15 years after repair of tetralogy of Fallot. During routine follow-up, a false aneurysm in the area of noncoronary sinus was diagnosed and repaired 45 days after the root replacement. Patient 10 acquired endocarditis and underwent aortic homograft implantation 34 days after root replacement.

\section{DISCUSSION}

Our policy is, if clinically possible, to wait until the size of the aortic root permits implantation of an adult size graft for a valve-sparing procedure. Root dilatation is seldom associated with severe aortic insufficiency or dissection in children. Such natural history of aortic root dilatation in children usually permits an elective aortic root replacement with an adult-size graft.

The largest study on valve-sparing aortic root replacement was recently performed at the Johns Hopkins Hospital by Patel and colleagues. ${ }^{1}$ This study of 56 children who underwent valve-sparing root remodeling $(\mathrm{n}=12)$ and reimplantation $(\mathrm{n}=44)$ demonstrated that reimplantation was superior to remodeling. Likewise, Roubertie and colleagues ${ }^{2}$ reported 14 valve-sparing root replacements in children and concluded that remodeling yielded disappointing results and should be abandoned in the pediatric population. We support this notion that reimplantation technique is superior ${ }^{1-3}$ because our only patient who had remodeling required the Bentall procedure 4 years later as the result of progressive annular dilatation.

The valve-sparing procedure can be performed safely in children. Patel and colleagues ${ }^{1}$ had an operative mortality of $1.8 \%(1 / 56)$ and an overall mortality of $7 \%(4 / 56)$ at a mean follow-up of 5.2 years. Roubertie and colleagues ${ }^{2}$ reported an operative mortality of $7.1 \%(1 / 14)$ and no late death at a mean follow-up of 6 years.

Patel and colleagues ${ }^{1}$ reported an overall reoperation rate of $9.1 \%(5 / 55)$, which included $4(33 \%, 4 / 12)$ aortic valve reoperations in the remodeling group and $1(2.3 \%, 1 / 43)$ repair of distal pseudoaneurysm in the reimplantation group. Roubertie and colleagues ${ }^{2}$ reported an overall reoperation 
TABLE 1. Patient characteristics and outcomes

\begin{tabular}{|c|c|c|c|c|c|c|c|c|}
\hline Patient & Diagnosis & $\begin{array}{c}\text { Year of } \\
\text { operation }\end{array}$ & Age (y) & BSA $(\mathbf{m} 2)$ & Graft size $(\mathbf{m m})$ & Follow-up (y) & Late AR & Reoperation \\
\hline $1^{*}$ & Marfan syndrome & 2002 & 14.5 & 1.85 & 30 & 8.8 & None & Bentall procedure \\
\hline $2 \dagger$ & TOF & 2003 & 15.6 & 1.75 & 30 & 5.7 & Mild & False aneurysm repai \\
\hline $3 \ddagger$ & Taussig-Bing + CoA & 2006 & 12.8 & 1.44 & 26 & 4.3 & None & None \\
\hline 4 & Marfan syndrome & 2006 & 16 & 1.76 & 28 & 4.7 & None & None \\
\hline $5 \S$ & Loeys-Dietz syndrome & 2006 & 16.2 & 1.63 & 28 & 4.6 & None & None \\
\hline 6 & Takayasu arteritis & 2007 & 12.6 & 1.28 & 26 & 3.8 & None & None \\
\hline $7 \|$ & Tricuspid atresia, TGA, IAA, VSD & 2008 & 15 & 1.51 & 26 & 3.2 & Mild & None \\
\hline 8 & Marfan syndrome & 2009 & 10.1 & 1.58 & 26 & 1.9 & Mild & None \\
\hline 99 & TOF & 2010 & 17.4 & 1.96 & 30 & 2 & None & None \\
\hline 10 & Loeys-Dietz syndrome & 2011 & 7.4 & 0.73 & 24 & 0.1 & None & Aortic homograft \\
\hline
\end{tabular}

$B S A$, Body surface area; $A R$, aortic regurgitation; $T O F$, tetralogy of Fallot; CoA, coarctation of aorta; TGA, transposition of the great arteries; IAA, interrupted aortic arch; VSD, ventricular septal defect. *Previous mitral valve repair in 2001. †Previous TOF repair in 1988. †Previous atrial septal defect closure in 1997. §Previous CoA repair in 1993, arterial switch operation and VSD closure in 1994, and relief of subaortic stenosis in 1998. ||Previous IAA repair, atrial septectomy, and pulmonary artery banding in 1993, arterial switch operation in 1993, bidirectional cavopulmonary shunt in 1995, and Fontan procedure in 2000. \Previous TOF repair in 1992.

rate of $42.9 \%(6 / 14)$ that included $5(45.4 \%, 5 / 11)$ aortic valve reoperations in the remodeling group and $1(33 \%$, $1 / 3$ ) Bentall procedure in the reimplantation group.

At the present time, valve-sparing aortic root replacement with reimplantation of the native valve into a graft with sinuses seems superior to aortic root replacement with a homograft or a composite graft in children. ${ }^{1-3}$ Further long-term studies will be required to confirm or refute this notion.

\section{CONCLUSIONS}

Valve-sparing aortic root replacement in children provides good intermediate outcomes. Aortic valve reimplantation into a graft with sinuses is the technique of choice.

\section{References}

1. Patel ND, Arnaoutakis GJ, George TJ, Allen JG, Alejo DE, Dietz HC, et al. Valvesparing aortic root replacement in children: intermediate-term results. Interact Cardiovasc Thorac Surg. 2011;12:415-9.

2. Roubertie F, Ben Ali W, Raisky O, Tamisier D, Sidi D, Vouhe PR. Aortic roo replacement in children: a word of caution about valve-sparing procedures. Eur J Cardiothorac Surg. 2009;35:136-40.

3. Vricella LA, Williams JA, Ravekes WJ, Holmes KW, Dietz HC, Gott VL, et al. Early experience with valve-sparing aortic root replacement in children. Ann Thorac Surg. 2005;80:1622-6.

4. Konstantinov IE, Fricke TA, d'Udekem Y, Robertson T. Aortic dissection and rupture in adolescents after tetralogy of Fallot repair. J Thorac Cardiovasc Surg. 2010;140:e71-3.

5. Gautier M, Detaint D, Fermanian C, Aegerter P, Delorme G, Arnoult F, et al Nomograms for aortic root diameters in children using two-dimensional echocardiography. Am J Cardiol. 2010;105:888-94.

\title{
Direct visualization of the aortic cusp from the left ventricle during aortic root reimplantation
}

\author{
Yutaka Okita, PhD, MD, Takanori Oka, MD, Shunsuke Miyahara, MD, and Kenji Okada, MD, PhD, \\ Hyogo, Japan
}

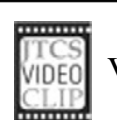

Video clip is available online.

From the Department of Cardiovascular Surgery, Kobe University, Hyogo, Japan. Disclosures: Authors have nothing to disclose with regard to commercial support. Received for publication March 19, 2012; revisions received April 2, 2012; accepted for publication May 7, 2012.

Address for reprints: Yutaka Okita, PhD, MD, Department of Cardiovascular Surgery,

Kobe University, 5-7-1 Kusunoki-cho, Chuo-ku, Kobe Hyogo 650-0017, Japan

(E-mail: yokita@med.kobe-u.ac.jp).

J Thorac Cardiovasc Surg 2012;144:981-2

$0022-5223 / \$ 36.00$

Copyright $(92012$ by The American Association for Thoracic Surgery

http://dx.doi.org/10.1016/j.jtcvs.2012.05.002
The patient was 52-year-old man who was diagnosed with annuloaortic ectasia and aortic valve regurgitation. $\mathrm{He}$ was asymptomatic; however, the transthoracic and transesophageal echocardiograms revealed that he had severe aortic regurgitation (regurgitation volume, $73 \mathrm{~mL}$; regurgitant fraction, $43 \%$; left ventricular diastolic dimension, 70 $\mathrm{mm}$; systolic dimension, $54 \mathrm{~mm}$, and ejection fraction, $45 \%$ ). The aortic valve was tricuspid, and the diameter of the ventricular aortic junction, sinus of Valsalva, and sinotubular junction was 26,45 , and $45 \mathrm{~mm}$, respectively.

He underwent aortic root replacement with a valvesparing technique. The aortic root was replaced with a 28$\mathrm{mm}$ Valsalva graft (Terumo Medical, Somerset, NJ) with 12 reinforced 3-0 polyester mattress sutures in the first 